\title{
Gender role conflict: Is it a predictor of marital dissatisfaction? A cross sectional study in Tehran
}

\author{
Abbas Pourshahbaz ${ }^{1}$, Mehrdad Eftekhar Ardebili², Behrouz Dolatshahi ${ }^{1}$, Hadi Ranjbar², Mozhgan Taban*2 (D) \\ Received: 16 May 2019 \\ Published: 24 Jul 2020
}

\section{Abstract}

Background: Gender role, sex-oriented attitudes, behaviors, cognitions, and emotions play an essential role in interpersonal relationships. Along with other factors, marital relationships and satisfaction can also be affected by a person's gender role. The increased rate of divorce is related to a decrease in marital satisfaction. The aim of this study was to evaluate the predictor power of gender role conflict on marital satisfaction considering the role of demographic variables (age, income, number of children, and number of family members), marriage-related factors (duration of the marriage, family functioning), and mental health disorder.

Methods: This was a cross sectional study. Participants were selected from couples who were attending West of Tehran health center. A total of 123 married couples aged 18 to 60 years who did not have mental or other medical disorders were recruited. Data gathering tools were McMaster Family Assessment Device (FAD), ENRICH Marital Satisfaction Scale, Bem Sex-Role Inventory (BSRI), a sociodemographic questionnaire, and Brief Symptom Inventory (BSI). Pearson correlation, chi-square, t test, ANOVA, Scheffe post hoc, and linear regression tests were used to analyze the data. Data were analyzed using SPSS 16, and in all statistical tests, significance level was set at $\mathrm{p}<0.05$.

Results: No significant correlations were observed between marital satisfaction and age, number of family members, duration of the marriage, number of children, and income $(\mathrm{p}>0.05)$. The presence of gender role conflict was correlated with lower marital satisfaction. Family functioning, gender role conflict, and presence of psychotic problems were predictors of marital satisfaction $\left(\mathrm{p}<0.001, \mathrm{R}^{2}=0.419\right)$.

Conclusion: Screening couples who applied for divorce due to psychiatric problems and gender role conflict and evaluating their family functioning may have a positive effect on reduction of divorce rate.

Keywords: Marital relationship, Satisfaction, Gender role, Psychology, Family

Conflicts of Interest: None declared

Funding: None

*This work has been published under CC BY-NC-SA 1.0 license.

Copyright $\odot$ Iran University of Medical Sciences

Cite this article as: Pourshahbaz A, Eftekhar Ardebili M, Dolatshahi B, Ranjbar H, Taban M. Gender role conflict: Is it a predictor of marital dissatisfaction? A cross sectional study in Tehran. Med J Islam Repub Iran. 2020 (24 Jul);34:84. https://doi.org/10.47176/mjiri.34.84

\section{Introduction}

Gender role is a construct demonstrating sex-oriented

Corresponding author: Mozhgan Taban, taban.m@iums.ac.ir

1. Department of Clinical Psychology, University of Social Welfare and Rehabilitation Sciences, Tehran, Iran

2. Mental Health Research Center, Psychosocial Health Research Institute, Iran university of medical sciences, Tehran, Iran attitudes, behaviors, cognitions, and emotions which are

\section{$\uparrow$ What is "already known" in this topic:}

Gender role is defined as the relative degree of a person's feminine or masculine psychological traits. Gender role conflict is the noncompliance of individuals' gender role with their assigned sex. There is evidence indicating that gender role is related to marital satisfaction. The evidence regarding the effect of gender role conflict is not convincing.

\section{$\rightarrow$ What this article adds:}

Gender role conflict was related to low marital satisfaction and those who had feminine and androgynous gender roles reported more marital satisfaction. Some of the feminine characteristics, which are a combination of complex behavioral and emotional interactions, can enhance the relationships. These results can be used in marital counseling and therapy. 
considered typically masculine or feminine in a particular cultural context (1). Also, gender role is the relative degree of a person's femini ne or masculine psychological traits. There are 4 gender role stereotypes based on masculinity and femininity. People with masculine stereotype have high masculinity and low femininity. Feminine stereotype indicates low masculinity and high femininity. High masculinity and high femininity is the characteristic of androgynous stereotype. There is also an undifferentiated stereotype, which is related to low masculinity and low femininity $(2,3)$.

Gender role conflict is the noncompliance of an individual's gender role with her/his assigned sex. Sex-oriented personal characteristics of individuals with gender role conflict are not compatible with the ones that the society or cultural context expect from them. The conflict can affect interpersonal relationships, especially in the family (4). There is evidence indicating that gender role is related to marital satisfaction (5-8). The results of previous studies showed that people with androgynous gender role have higher marital satisfaction $(7,9,10)$. However, the evidence regarding the effect of gender role conflict is not convincing. Gender role conflict occurs when a person's gender role is different from his/her sex. While gender roles are cultural/context-based, there is not enough evidence on the relationship between specific stereotypes and marital satisfaction in the Iranian population.

The rate of divorce has significantly increased in recent years in Iran, and accordingly, we have witnessed a sharp decrease in the ratio of marriage to divorce from 9.4 in 2004 , to 6.5 in 2009 , and to 4.2 in 2014 . Iran has had the highest growing rate of divorce in Islamic countries and the Middle East, which has become a serious social concern and needs special attention (11-13). Divorce is a multidimensional phenomenon and is affected by several factors. Marital satisfaction is one of the most influential factors in divorce, and several studies have supported a robust association between marital satisfaction and divorce (14-16). Marital satisfaction is a personal feeling of happiness or pleasure in a relationship. It also reveals spouses' happiness considering all aspects of marriage (17). It is the amount of desire and needs fulfillment of couples by each other, which is a subjective evaluation of the marriage. It reveals the perceived benefits and consequences of being in a marital relationship (18). Although marital satisfaction has been the subject of many studies and several effective factors have been identified, some dimensions that are affecting interpersonal relationships have been less studied.

Family functioning is another factor which can affect marital satisfaction. It includes activities and relationships and shows the quality of support, acceptance, and com- munication between family members. It includes the processes which are implemented by families in their lives to achieve goals, respond to challenges, and support and improve family members' health and development (19). Family functions are defined in conflictual (negative) and cohesive and supportive (positive) ways (20). The relationship between family functioning and marital satisfaction is a less developed area of study in Iranian families.

Gender role conflict and family functioning may be related to the presence of mental health problems. There is a considerable body of evidence regarding the relationship between the presence of a mental health problem and marital dissatisfaction (21-23). However, in many cases, mental health problems remain undiagnosed, and the focus of most of the studies has been on people with diagnosed disorders. Marital satisfaction, because of its role on stability and productivity of families, has been the subject of several studies. The relationship between family characteristics and marital satisfaction has also been comprehensively explored (24-27). However, the predictive power of essential factors like gender role conflict, the presence of an undiagnosed mental health disorder, and family functioning has not been previously examined.

Identifying the factors that can have the most significant impact on marital satisfaction is especially important, as it can help the counselor in a more accurate assessment. We did not find any study regarding the effect of gender role conflict, family functioning, and undiagnosed mental health problems on the marital satisfaction of Iranian couples. Therefore, the aim our study was to evaluate the predictor power of gender role conflict on marital satisfaction considering the role of demographic variables (age, income, number of children, and number of family members), marriage-related factors (duration of the marriage, family functioning), and a mental health disorder.

\section{Methods}

This was a cross sectional study for which participants were recruited from couples who attended West of Tehran health center from Aug 2017 to Jun 2018. Inclusion criteria were as follow: (1) being married for at least 2 years, (2) aged 18- 60 years, (3) not having known mental or other medical disorders (according to them). The sample size was calculated using $G^{*}$ Power (v. 3.1.9.2), with an alpha of 0.05 and power of $80 \%$. We used quota sampling method to increase the representativeness of the participants. Two variables (family size and income) were selected for sample stratification. The information on income and family size was received from the Statistical Center of Iran. Then, we drew a table with income quartiles in rows and family sizes' quartiles in columns (Table 1). The income classes were low (less than 20 million

Table 1. The quota sampling of the participants based on family size and income

\begin{tabular}{lcccc}
\hline & \multicolumn{3}{c}{ Family Size } \\
\cline { 2 - 5 } Income & Two & Three & Four & Five and more \\
\hline Low & 11 & 15 & 15 & 7 \\
Low-middle & 6 & 8 & 7 & 3 \\
High-middle & 6 & 7 & 7 & 3 \\
High & 6 & 8 & 3 & 24 \\
Total & 29 & 39 & 36 & 24 \\
\hline
\end{tabular}


Iranian Rials), middle-low (20 to 30 million Rials), highmiddle (30 to 40 million Rials) and high (more than 40 million Rials). We recruited samples based on the proportion on each cell.

The first author explained the study to the participants, and they all provided informed consent to participate in the study. Then, the instruction for completing the questionnaires was provided to couples, and an envelope containing one pair of study instruments was given to them. They were asked to complete the questionnaires separately and return it anonymously within 2 weeks to the health center.

\section{Study instruments}

Five questionnaires were used, including McMaster Family Assessment Device (FAD), ENRICH Marital Satisfaction Scale, Bem Sex-Role Inventory (BSRI), a sociodemographic questionnaire, and Brief Symptom Inventory (BSI). The sociodemographic questionnaire was a researcher-made scale, including questions regarding age, educational level, and duration of marriage, family size, and number of children.

The FAD is based on the McMaster Model of Family Functioning (MMFF), which measures the structural, organizational, and transactional characteristics of the family and has 6 dimensions. The questionnaire has 60 items about a family and respondents should rate how well each statement defines their own family. Each statement receives a score from 1 to 4 . Higher scores indicate poorer levels of family functioning. The scale was translated into Persian by Yoosefi (2012). He reported good construct validity and high internal consistency for the Persian version (Alpha $=0.83)(28)$. Internal consistency of the scale was $\alpha=0.85$ in this study.

ENRICH Marital Satisfaction Scale has 115 items with 12 subscales, including Idealistic distortion, marital satisfaction, personality issues, communication, conflict resolution, financial management, leisure activities, sexual relationship, children and parenting, family and friends, equalitarian roles, and religious orientation. Each item is rated from 1 (Completely agree) to 5 (Completely disagree). Higher scores on this scale indicate higher marital satisfaction. This scale was translated into Persian by Sanai (29). The reliability of the scale was calculated using Cronbach's alpha in the present study $(\alpha=0.97)$.

Bem Sex-Role Inventory (BSRI), the most commonly used gender role measurement tool across countries and age groups, measures gender role perception. It focuses on individual's culturally defined sense of gender orientation. It has 3 subscales, including masculine, feminine, and neutral, each of which having 20 items (Total items = 60 ), are scored from 1 (never or almost never) to 7 (always or almost always). The BSRI score is the relative weight of the masculinity score and femininity score. The items' mean scores higher than 4.9 are considered as masculinity. Femininity score is the mean of the 20 personality characteristics on the Femininity scale and masculinity score is the mean of the 20 personality characteristics on the masculinity scale. These 2 subscores are used to determine the total BSRI score and classification. BSRI score is calculated by subtracting the masculinity score from the femininity score. Higher positive and higher negative scores indicate more feminine and masculine characteristics, respectively. Scores close to zero indicate the presence of both feminine and masculine characteristics, which is named androgynous. We considered a cut point of 4.9 in determining whether someone was scored as high in feminine or masculine traits. If someone had a feminine score higher than 4.9 and masculine score lower than 4.9, we considered him/her as a feminine person. If someone had a masculine score higher than 4.9 and feminine score lower than 4.9 , we considered him/her as a masculine person. Participants who scored lower than 4.9 on both scales were considered undifferentiated. Participants who scored higher or equal to 4.9 on both scales were considered androgynous. The English version of BSRI had high internal consistency for feminine and masculine subscales, 0.86 and 0.82, respectively. Mehrabizadeh Honarmand and Ali Akbari Dehkordi (30) translated this scale into Persian and reported Cronbach's alpha for both subscales $(0.99$ for feminine and 0.75 for masculine). The reliability of the scale was calculated using Cronbach's alpha in the present study ( $\alpha=0.86$ for feminine and $\alpha=0.84$ for masculine). If an individual gender role was not compatible with his/her assigned sex, then she/he was considered as a subject with gender role conflict. Also, all individuals with undifferentiated gender roles were considered as persons with gender role conflict.

Brief Symptom Inventory (BSI) is a 53-item screening tool for mental health problems. It is the shortened version of the Symptoms Checklist-90. Nine symptom dimensions, including somatization, obsession-compulsion, interpersonal sensitivity, depression, anxiety, hostility, phobic anxiety, paranoid ideation, and psychoticism, were covered by this scale. It has also 3 global indices (Global Severity Index, Positive Symptom Distress Index, and Positive Symptom Total). Moreover, BSI has 4 additional items that are not included in any domain. Global Severity Index (GSI) is the sum of the 9 symptom dimensions plus the 4 additional items divided by the total number of items to which the individual responded. We changed raw scores to $\mathrm{z}$ scores. Then, we computed GSI $\mathrm{T}$ using the following formula: $\mathrm{T}=(\mathrm{Z} \times 10)+50$. We considered GSI $\mathrm{T}$ scores higher than 63 as an indication of the presence of a mental health problem. The reliability of 9 dimensions ranged from 0.71 on psychoticism to 0.85 on depression. The scale was translated by Mohammadkhani, Dobson (31), and they reported Cronbach's alpha of 0.70 and testretest reliability of 0.68 to 0.91 . The Cronbach's alpha for this scale was 0.86 in our study.

Data were analyzed using SPSS 16 . The normality of the distribution of the variables was examined using the Kolmogorov Smirnov test. Pearson correlation was used to evaluate the correlation between marital satisfaction and age, number of family members, duration of marriage, number of children and income. ANOVA and Scheffe post hoc tests were used to compare marital satisfaction based on gender roles. Chi square was used to evaluate the correlation between mental health problem and gender roles. Independent samples $t$ test was used to compare 
marital satisfaction based on mental health problem and gender role conflict. Linear regression was used to estimate the effect of variables on marital satisfaction. Significance level was considered as $\mathrm{p}<0.05$ in all tests.

The study protocol was approved by the Human Ethics Committee at the University of Social Welfare and Rehabilitation Sciences, Tehran, Iran (IR.USWR.REC. 1395.49). There was a brief anonymous consent form on the first page of instruments. The aim and procedures of this study were explained to the participants on the second page. All data were treated anonymously. Study participants were assured that their response would remain confidential.

\section{Results}

A total of 300 questionnaires were distributed among 150 couples. At the end of sampling, 123 couples returned the questionnaires ( $82 \%$ response rate). The sociodemographic characteristics of the study samples are presented in Table 2.

The comparison of marital satisfaction based on gender roles is presented in Table 3. There was a significant difference in marital satisfaction between different gender roles $(p<0.05)$. Based on this table, participants with a feminine gender role had the highest marital satisfaction scores, which was significantly higher than those with masculine and undifferentiated gender roles $(\mathrm{p}<0.05)$. The difference between marital satisfaction of participants with feminine gender role and androgynous ones was not statistically significant. Participants with androgynous gender role had higher marital satisfaction compared to those with masculine and undifferentiated gender roles.

In this study, 125 (50.8\%) participants had gender role conflict. There was a significant difference in marital satisfaction between participants who had gender role conflicts and those who had not. Also, 23 individuals (18.5\%) who had gender role conflict had a psychiatric problem, based on BSI. A significant correlation was observed between gender role conflict and the presence of psychiatric problems $(p=0.005)$. A contingency table analysis of Bem gender roles with BSI problem revealed a significant relationship between these 2 variables. The mean $\pm \mathrm{SD}$ of marital satisfaction, BSI, and family functioning scores of individuals based on the presence of a psychiatric problem and gender role conflict are presented in Table 4. Based on the results of the Table 4, people with mental health problem had significantly higher problems in family functioning and also had lower marital satisfaction. Furthermore, individuals with gender role conflict had lower marital satisfaction and higher mental health problem scores.

No significant correlations was found between marital satisfaction and age $(r=-0.12, p=0.07)$, number of family members $(\mathrm{r}=-0.01, \mathrm{p}=0.8)$, duration of marriage $(\mathrm{r}=-0.06$, $\mathrm{p}=0.32)$, number of children $(\mathrm{r}=-0.06, \mathrm{p}=0.32)$, and income $(r=-0.06, p=0.32)$. The comparison of psychiatric problems in individuals with different gender roles is pre-

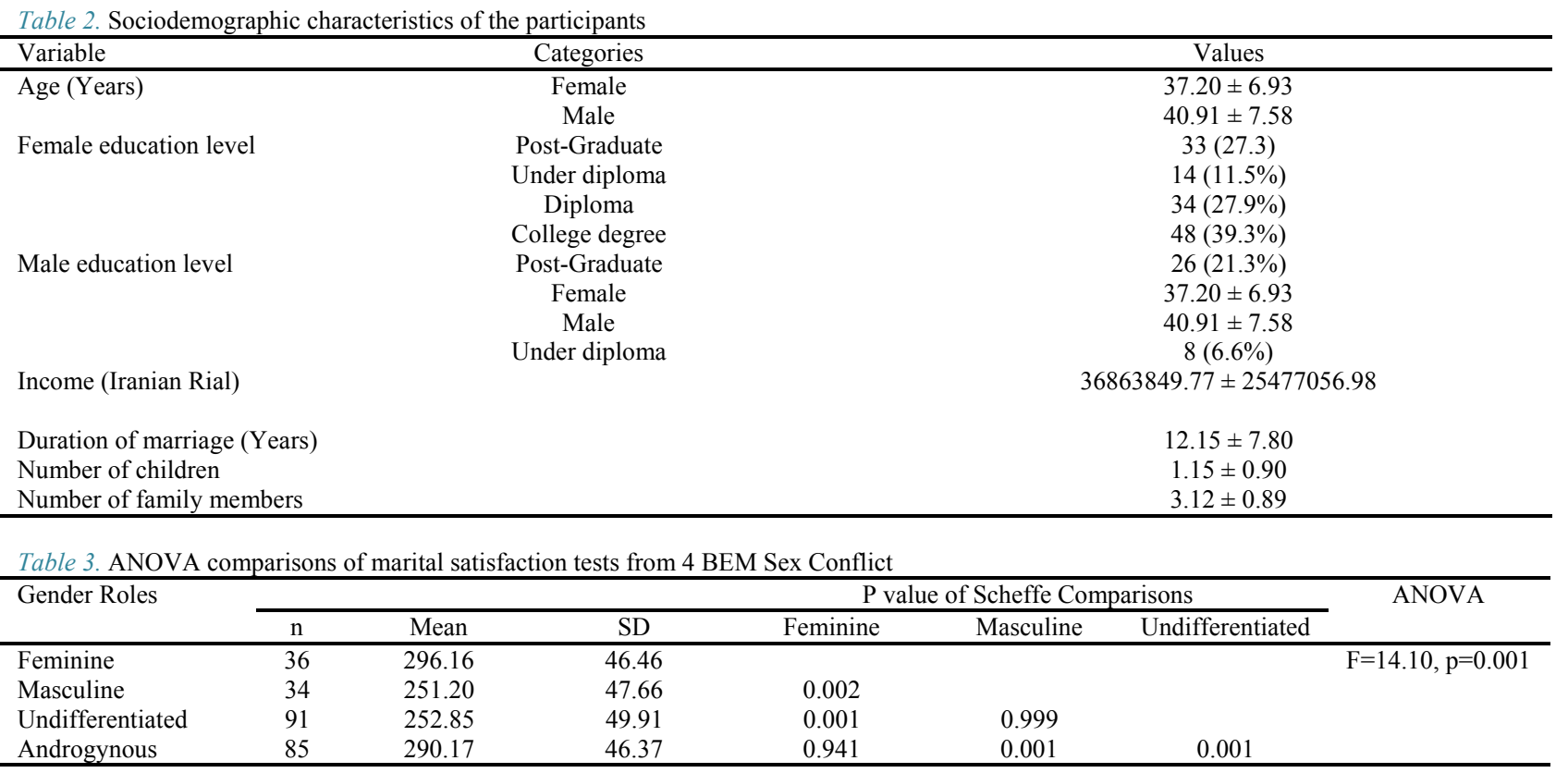

Table 4. The comparison of family functioning and marital satisfaction and BSI scores based on the presence of psychiatric problems and gender role conflict

\begin{tabular}{|c|c|c|c|c|c|c|c|c|c|c|}
\hline & \multicolumn{4}{|c|}{ Mental Health Problem } & \multicolumn{6}{|c|}{ Gender Conflict } \\
\hline & \multicolumn{2}{|c|}{ FAD } & \multicolumn{2}{|c|}{ MS Total } & \multicolumn{2}{|c|}{ FAD } & \multicolumn{2}{|c|}{ BSI Score } & \multicolumn{2}{|c|}{ MS Total } \\
\hline & No & Yes & No & Yes & No & Yes & No & Yes & No & Yes \\
\hline Mean & 135.7 & 141.52 & 280.98 & 215.06 & 135.59 & 137.33 & 0.62 & 0.84 & 283.58 & 260.52 \\
\hline SD & 11.97 & 13.69 & 46.39 & 45.44 & 13.24 & 11.27 & 0.48 & 0.60 & 46.40 & 54.00 \\
\hline $\mathrm{T}$ test & \multicolumn{2}{|c|}{$\begin{array}{c}\mathrm{p}=0.01, \\
95 \% \mathrm{CI}(-10.43,-1.19)\end{array}$} & \multicolumn{2}{|c|}{$\begin{array}{c}\mathrm{p}=0.001, \\
95 \% \mathrm{CI}(48.39,83.43)\end{array}$} & \multicolumn{2}{|c|}{$\begin{array}{c}\mathrm{p}=0.267, \\
95 \% \text { CI }(-4.82,1.34)\end{array}$} & \multicolumn{2}{|c|}{$\begin{array}{c}\mathrm{p}=0.002, \\
95 \% \mathrm{CI}(-0.35,-0.08)\end{array}$} & \multicolumn{2}{|c|}{$\begin{array}{c}\mathrm{p}=0.001, \\
95 \% \text { CI }(10.39,35.72)\end{array}$} \\
\hline
\end{tabular}


A. Pourshahbaz, et al.

Table 5. Comparison of psychiatric problems in individuals with different gender roles

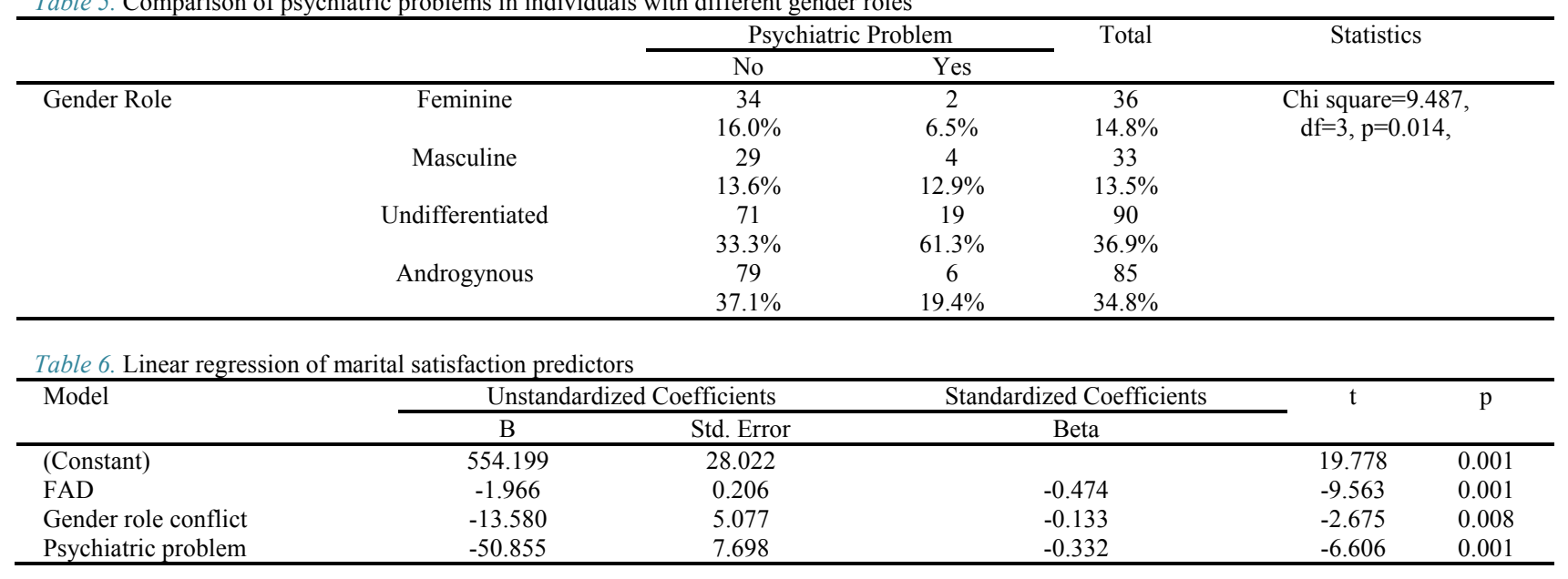

sented in Table 5.

Based on the results of linear regression, family functioning, gender role conflict and presence of psychotic problems were predictors of marital satisfaction $\mathrm{p}<0.001$, $\left.\mathrm{R}^{2}=0.419\right)$. Participant's marital satisfaction is equal to $554.19-1.96$ (FAD score) - 13.58 (if there was a gender role conflict) -50.85 (if there was a psychiatric problem). Individuals with gender role conflict had lower scores of marital satisfaction even after justifications based on psychiatric problems and family functioning (Table 6).

\section{Discussion}

Our results showed that the presence of gender role conflict, decrease in family function, and the existence of a mental health problem are predictors of low marital satisfaction. Age, number of family members, duration of the marriage, number of children, and income were not related to marital satisfaction.

Participants with gender role conflicts had lower marital satisfaction scores. Also, those who had feminine and androgynous gender roles had higher marital satisfaction. Having an androgynous gender role is a predictor of better marital satisfaction, which has been shown in several studies. Diaz and Bui (32) indicated that because individuals with androgynous gender role are unified and can resolve gender stereotypes and are not restricted to one gender, they are more flexible and adaptable to different circumstances. In our study, individuals with a feminine gender role had higher marital satisfaction compared to those who had undifferentiated and masculine gender roles. Their scores also were a little higher than people with androgynous gender role, but the difference was not statistically significant. This is an interesting result which needs future consideration.

Gender role is a social construct which is influenced by social and cultural changes $(4,8)$. Based on Bem theory, gender role is a schema and its influence on the person's attitude, experiences, emotions, thoughts, and eventually, behaviors $(3,9)$. Despite the existence of social pressure on individuals to match their gender role with their sex, it seems that women and men develop some characteristics that are not matched with their sex. As a result, we are witnessing the formation of masculine and feminine characteristics in women and men, respectively. Having personal feminine characteristics such as being cheerful, affectionate, loyal, understanding, and sensitive to the needs of others can affect personal relationships; and as a result, they can increase marital satisfaction. These characteristics can have a positive effect on the relationships of both genders. Having the personal characteristics of both gender in people with androgynous gender role can increase their understanding of their partners' emotions and behaviors. Higher marital satisfaction of participants with feminine and androgynous gender roles might have been due to their feminine sexual characteristics (eg, gentle, warm, and sympathetic and not using harsh language). Feminine characteristics can enhance a marital relationship, which is a combination of complex behavioral and emotional interactions. Curun (33) conducted a study to assess the effect of perception of people in romantic relationships about their partners' gender roles. Their results showed that the romantic satisfaction of individuals who perceived their partner gender role as androgynous was higher than others.

Gender role conflict can be associated with other variables which can negatively affect marital satisfaction. Some studies showed that people with feminine and androgynous gender roles have high marital satisfaction (34). They have better relationships with themselves and their partners. People with undifferentiated gender roles have more problems with coping and having a good relationship with their partners. In recent years, Iranian women have been able to make significant progress in the professional and scientific fields. Also, the traditional roles of men have been changed due to economic, cultural, and social changes. One of the interesting findings of this study was observing gender role conflict in more than half of the study samples. Gender role conflict is having perceived gender roles which are not compatible with biological sex. Most of participants with gender role conflict had undifferentiated gender role, which means the scores of both feminine and masculine subscales were low. The advances in the society and the redefinition of gender roles are important in the interpretation of these results. 
Increase in the role of women in the society and more acceptance of feminine characteristics in men are 2 essential factors which can be the reason for the obtained results.

Results of previous studies regarding the relationship between family functioning and marital satisfaction are controversial. Some studies support the notion of negative effect of family functioning on marital satisfaction, while some others did not find this effect (35-38). The decrease in family functioning indicates the poorer processes and use of conflictual ways. High scores in family functioning scores indicate that family members use poorer processes in their relationship with each other. It can negatively affect the satisfaction of the couple regarding their marital relationships. When the FAD scores are high, they indicate an increase in the use of conflictual ways of interaction and decrease in the use of cohesive and supportive ways. In such families, interactions between couples are more hostile, and it can reduce their marital satisfaction.

Based on our results, having a mental health disorder was another predictor of low marital satisfaction. Chronic diseases such as mental health disorders are known as predictors of low marital satisfaction $(39,40)$. In our study, people who completed the questionnaires were not aware of their mental health problem. The results of previous studies have shown that many people in the community are not aware of their own mental health problems. In this study, we used BSI, a reliable and powerful instrument for diagnostic purposes, to assess symptoms of psychological disorders.

Mental health is "a state of well-being in which every individual realizes his or her own potential, can cope with the normal stresses of life, can work productively and fruitfully, and is able to make a contribution to her or his community." (41) Based on this definition, individuals with mental health disorders have a problem with coping, working productively, and contributing to the society. The prevalence of mental health disorders in Iran is about $21 \%$ (25.9\% women and $14.9 \%$ men). While most psychological disorders often go undiagnosed and untreated (42), they can negatively affect the family and marital satisfaction. When people do not have enough insight regarding their disease, they do not seek treatment and the negative impacts of disease increase over time.

We did not find a strong relationship between age, number of family members, duration of the marriage, number of children, and income and marital satisfaction. Some studies showed a negative relationship between the increase in age and marital satisfaction $(20,43,44)$. Some studies reported no significant relationship between these 2 variables $(45,46)$. There is also some evidence that shows an increase in age can positively affect marital satisfaction (47). The relationship between age and marital satisfaction is highly dependent on the sample. The evidence regarding the relationships between the duration of the marriage, number of family members, number of children, and income with marital satisfaction are also controversial (47-50).

One limitation of this study was the number of questions in data gathering scales, which could reduce the ac- curacy and precision of responses. For this reason, the researcher asked study participants to bring the questionnaire home and complete it on their convenient time. To recruit a representative sample size, we used the number of family members and income classification in quota sampling. Nevertheless, because of the sociodemographic characteristics of people who referred to the center, their education level was higher than the sampling population. Thus, more variables should be used in quota sampling in future studies. The small sample size was one of our study limitations, which can reduce the generalizability of the results. Nevertheless, using several variables can help to capture more vivid picture from factors that can affect marital satisfaction. Application of several questionnaires in large samples is not feasible; however, we recommend larger samples to have more power.

\section{Conclusion}

Family is the cornerstone of any society, especially in Middle Eastern cultures like Iran. Marital satisfaction plays a significant role in the stability of this social unit. Several studies explored the effective factors that can influence satisfaction with marriage. Based on our results, gender role conflict is related to lower marital satisfaction. People with more feminine characteristics had higher marital satisfaction. Low family functioning and having psychiatric problems were also strong predictors of low marital satisfaction. The results of this study can be used in marital counseling. Screening couples who filed for divorce due to psychiatric problems and gender role conflict and evaluating their family functioning may have a positive effect on the reduction of divorce rate. Considering that having good characteristics of both genders can have a positive effect on marital satisfaction, increasing the families' knowledge and leaving traditional roles can be helpful in better coping and increasing marital satisfaction.

\section{Conflict of Interests}

The authors declare that they have no competing interests.

\section{References}

1. Lampis J, Cataudella S, Busonera A, De Simone S, Tommasi M. The moderating effect of gender role on the relationships between gender and attitudes about body and eating in a sample of Italian adolescents. Eat Weight Disord. 2019;24(1):3-11.

2. Donnelly K, Twenge JM. Masculine and Feminine Traits on the Bem Sex-Role Inventory, 1993-2012: a Cross-Temporal Meta-Analysis. Sex Roles. 2017;76(9):556-65.

3. Alavi K, Jalali Nadoushan AH, Eftekhar M. Masculine and Feminine Gender Roles in Healthy Iranian Population According to Two Different Constructs: Bem Sex Role Inventory vs. GM and GF Scales of MMPI-2. Iran J Psychiatry Clin Psychol. 2014;20(2):121-33.

4. Kaya A, Iwamoto DK, Brady J, Clinton L, Grivel M. The role of masculine norms and gender role conflict on prospective well-being among men. Psychol Men Masc. 2018;26:1-7.

5. Zara A, Yücel FG. The Contribution of Projective Identification, Conflict Resolution Styles, Gender Roles on Marital Satisfaction. J Clin Psychiatry 2017;20(2):76-83.

6. Keyhan F, Saber S. Predicting Marital Satisfaction Based on Gender Beliefs and Thinking Styles of Married Women in Tehran. J Community Health. 2016;3(3):200-10.

7. Wood CA, Helms HM, Supple AJ, Perlman D. Gender-typed 
attributes and marital satisfaction among Mexican immigrant couples: A latent profile approach. J Fam Psychol. 2015;29(3):321.

8. Maaref M, Khalili S, Hejazi E, Golamali LM. The relationship between identity style, gender role and marital satisfaction in married couples. J Psychol. 2015;18(4):365-80.

9. Azmoude E, Firoozi M, Sahebzad ES, Asgharipour N. Relationship between gender roles and sexual assertiveness in married women. Int J Commun Bas Nurs Midwif. 2016;4(4):363.

10. Ta VP. A Meta-Analytic Review of Gender-Role Dimensions and Relationship Satisfaction. J Relatsh Res. 2017;8.

11. Farzanegan MR, Gholipour HF. Divorce and the cost of housing: evidence from Iran. Rev Econ Househ. 2016;14(4):1029-54.

12. Farzanegan MR, Gholipour HF. Does Gold Price Matter for Divorce Rate in Iran? J Fam Econ Issues. 2018;39(4):588-99.

13. Sadeghi R, Agadjanian V. Attitude and Propensity to Divorce in Iran: Structural and Ideational Determinants. J Divorce Remarriage. 2019:1-22

14. DeLongis A, Zwicker A. Marital satisfaction and divorce in couples in stepfamilies. Curr Opin Psychol. 2017;13:158-61.

15. Weiss B, Lavner JA, Miller JD. Self-and partner-reported psychopathic traits' relations with couples' communication, marital satisfaction trajectories, and divorce in a longitudinal sample Personal Disord. 2016 ;9(3):239-249

16. Birditt KS, Wan WH, Orbuch TL, Antonucci TC. The development of marital tension: Implications for divorce among married couples. Dev Psychol. 2017;53(10):1995.

17. Aman J, Abbas J, Nurunnabi M, Bano S. The Relationship of Religiosity and Marital Satisfaction: The Role of Religious Commitment and Practices on Marital Satisfaction Among Pakistani Respondents. Behav Sci (Basel). 2019;9(3).

18. Teal S. The Association of Attachment and Marital Satisfaction Mediated by Implicit Theories of Relationships. CPY Dissertations. 2018;28.

19. Al-Krenawi A, Graham JR, Al Gharaibeh FJD, Society. The impact of intellectual disability, caregiver burden, family functioning, marital quality, and sense of coherence. Disabil Soc. 2011;26(2):139-50.

20. Abdi S, Amiri S, Mohammadi S. Relationship between family processes and social support through mediating marital satisfaction: Structural model of social support in major depression women. J Appl Environ Biol Sci. 2015;4:48-54.

21. Talaizadeh F, Bakhtiyarpour S. The relationship between marital satisfaction and sexual satisfaction with couple mental health. J Clin Psychol. 2016;10(40):37-46.

22. Kalhor M, Olyaie N. Relationship between marital satisfaction and mental health of married women referring to health centers in Sanandaj, Iran in 2014. Glob J Health Sci. 2017;9(1):19.

23. Noorbala AA, Malek Afzali H, Abedinia N, Akhbari M, Moravveji A, Vaseghi F, et al. Mental Health Status and Marital Satisfaction of Pregnant Women Referring to Health Centers in Kashan, Iran. J School Pub Health Institute Pub Health Res. 2018;16(3):279-94.

24. Hajihasani M, Sim T. Marital satisfaction among girls with early marriage in Iran: emotional intelligence and religious orientation. Int J Adolesc Youth. 2018:1-10.

25. Samadaee-Gelehkolaee K, Mccarthy BW, Khalilian A, Hamzehgardeshi Z, Peyvandi S, Elyasi F, et al. Glob J Health Sci. 2016;8(5):96.

26. Zaheri F, Dolatian M, Shariati M, Simbar M, Ebadi A, Azghadi SB. Effective factors in marital satisfaction in perspective of Iranian women and men: A systematic review. Electron Physician. 2016;8(12):3369

27. Yazdani F, Kazemi A, Fooladi MM, Samani HR.Gynecology, Biology R. The relations between marital quality, social support, social acceptance and coping strategies among the infertile Iranian couples. Eur J Obstet Gynecol Reprod Biol. 2016;200:58-62.

28. Yoosefi N. An investigation of the psychometric properties of the mcmaster clinical rating scale (mcrs). Train Measur. 2012;3(7):83112 .

29. Sanai B. [Scales for assessment family and marriiage]. Tehran: Besat; 2009.

30. Mehrabizadeh Honarmand M, Ali Akbari Dehkordi M, Najarian B, Shokrkon H, Shehni Yeylagh M. Identification and comparison of gender types of employed women and their spouses on mental health, marital satisfaction and emotional intelligence. J Educ Psychol 2005;13(3):53-80.

31. Mohammadkhani P, Dobson KS, Amiri M, Ghafari FH.
Psychometric properties of the Brief Symptom Inventory in a sample of recovered Iranian depressed patients. Int J Clin Health Psychol. 2010;10(3):541-51.

32. Diaz T, Bui NH. Subjective well-being in Mexican and Mexican American women: The role of acculturation, ethnic identity, gender roles, and perceived social support. J Happiness Stud 2017;18(2):607-24.

33. Curun F. Sex Role Orientation and Romantic Relationship Satisfaction : A Study in Turkey. Interpersona. 2012;6(2):227-34.

34. Jackson J, Miller R, Oka M, Henry R. Gender differences in marital satisfaction: A meta-analysis. J Marriage Fam. 2014;76(1):105-29.

35. Jiang H, Wang L, Zhang Q, Liu Dx, Ding J, Lei Z, et al. Family functioning, marital satisfaction and social support in hemodialysis patients and their spouses. Stress Health. 2015;31(2):166-74.

36. Wang YH, Haslam M, Yu M, Ding J, Lu Q, Pan FJH, et al. Family functioning, marital quality and social support in Chinese patients with epilepsy. Health Qual Life Outcomes. 2015;13(1):10.

37. Pedro MF, RibeiroT, Shelton KH. Romantic attachment and family functioning: The mediating role of marital satisfaction. J Child Fam Stud. 2015;24(11):3482-95.

38. Parvandi A, Arefi M, Moradi A. The role of family functioning and couples communication patterns in marital satisfaction. Semi Ann J Fam Pathol Councel Enrich. 2016;2(1):54-65.

39. Wang Q, Wang D, Li C, Miller RBJA, Health M. Marital satisfaction and depressive symptoms among Chinese older couples. Aging Ment Health. 2014;18(1):11-8.

40. Vest BM, Cercone Heavey S, Homish DL, Homish GG. Marital satisfaction, family support, and pre-deployment resiliency factors related to mental health outcomes for reserve and national guard soldiers. Mil Behav Health. 2017;5(4):313-23.

41. Organization WH. Mental health: a state of well-being: World Health Organization; 2014 [updated August 2014]. Available from: https://www.who.int/features/factfiles/mental health/en/.

42. Lake CR. How academic psychiatry can better prepare students for their future patients. Part I: the failure to recognize depression and risk for suicide in primary care; problem identification, responsibility, and solutions. Behav Med. 2008;34(3):95-100.

43. Amiri M, Sadeqi Z, Hoseinpoor MH, Khosravi A. Marital Satisfaction and Its Influencing Factors in Fertile and Infertile Women. J Fam Reprod Health. 2016;10(3):139-45.

44. KatayoonAhangar RJ, Yaacob SN, Talib MA. Demographic factors and marital satisfaction among iranian married students in malaysia. asian journal of social sciences and humanities Asian J Res Soc Sci Hum. 2016;5:2.

45. Navid B, Mohammadi M, Sasannejad R, Dehkordi MA, Maroufizadeh S, Hafezi M, et al. Marital satisfaction and social support in infertile women with and without polycystic ovary syndrome. Middle East Fertil Soc J. 2018;23(4):450-5.

46. Boostani H, Hoseini SM, Khodadadi N, Froozi N. Marital Satisfaction in Women with Breast Cancer: A Comparison between Mastectomy and Breast Conserved patients. Biochem Pharmacol J. 2015;8(2):1237.

47. Esmaeili, NS, Schoebi, D. Research on correlates of marital quality and stability in Muslim countries: A review. J Fam Theory Rev. 2017;9:69-92.

48. Zaheri F, Dolatian M, Shariati M, Simbar M, Ebadi A, Azghadi SB. Effective Factors in Marital Satisfaction in Perspective of Iranian Women and Men: A systematic review. Electron Physician. 2016;8(12):3369-77

49. Samadaee-Gelehkolaee K, McCarthy BW, Khalilian A, Hamzehgardeshi Z, Peyvandi S, Elyasi F, et al. Factors Associated With Marital Satisfaction in Infertile Couple: A Comprehensive Literature Review. Glob J Health Sci. 2015;8(5):96-109.

50. Tavakol Z, Nikbakht Nasrabadi A, Behboodi Moghadam Z, Salehiniya H, Rezaei E. A review of the factors associated with marital satisfaction. Galen Med J. 2017;6(3):197-207. 